extraction of the lens to Edinburgh in 1922, and in 1932, in his Presidential Address to the Ophthalmological Society of the United Kingdom, he reported on a series of 257 cases with results which have never been surpassed. These two great contributions to British Ophthalmology were recognised by his election to Honorary Membership of the Society.

Dr. Sinclair also held, at various stages in his career, appointments as Surgeon to Leith Hospital and to the Royal Hospital for Sick Children, and he was also Consultant Ophthalmic Surgeon to the Department of Health for Scotland. In 1927 he was elected President of the Ophthalmological Section of the British Medical Association, from 19311933 he was President of the Ophthalmological Society of the United Kingdom, and in 1933 he was elected President of the Royal College of Surgeons of Edinburgh, a position which he occupied with dignity and authority. In 1928 he was appointed Honorary Surgeon Oculist to His Majesty the King in Scotland, an appointment which he was to hold for 24 years.

In 1935 the W. H. Ross Foundation for the Study of Prevention of Blindness was founded through the generosity of Mr. W. H. Ross, and it was on the advice of Dr. Sinclair that this munificent gift was used for research purposes. He became the first Chairman of the Medical Advisory Committee of the Foundation and he devoted the next 16 years of his life to this work.

A man of great culture and of complete integrity, Dr. Sinclair possessed a natural dignity and charm which endeared him to his patients and his friends. A keen fisherman, a good shot, and a great follower of rugby football, he never missed an international match in Edinburgh until a few years before his death.

In 1898 Dr. Sinclair married Mabel Kennedy, who died in 1947, and many will remember their gracious hospitality in their lovely Adam house in Charlotte Square. He is survived by a daughter and son to whom goes our deepest sympathy in the loss of their father, a true Highland gentleman and a great surgeon.

\title{
DORIS ROSE
}

Our readers will be sad to learn of the death on July 31 of Dr. Doris Rose (née Todd) of Eastbourne. She studied medicine at the Royal Hospital in London, qualified in 1923, and thereafter specialized in ophthalmology at Moorfields Eye Hospital where she worked for several years. In 1945 she was appointed to the Staff of the Princess Alice Hospital, Eastbourne, where she remained until her death. In this town she took an intense interest in all things ophthalmological, being President of the Eastbourne Medical Society in 1959, the first woman doctor to occupy this office. An excellent physician, a good surgeon, and a delightful personality, she became one of the most popular members of the medical community in the South of England. 